\title{
Nortriptyline versus fluoxetine in the treatment of major depressive disorder: a six-month, double-blind clinical trial
}

This article was published in the following Dove Press journal:

Clinical Pharmacology:Advances and Applications

10 January 2012

Number of times this article has been viewed

\author{
SN Hashemi' \\ HR Ghafarian Shirazi ${ }^{2,3}$ \\ A Mohammadi ${ }^{4}$ \\ GH Zadeh-Bagheri ${ }^{5}$ \\ KH Noorian ${ }^{5}$ \\ M Malekzadeh ${ }^{2}$ \\ 'Department of Psychiatry, Faculty \\ of Medicine, ${ }^{2}$ Research Center \\ of Social Factors Affecting Health, \\ Yasuj University of Medical Sciences, \\ Yasuj, ${ }^{3}$ School of Public Health, \\ Tehran University of Medical Sciences, \\ Tehran, ${ }^{4}$ Department of Psychiatry, \\ ${ }^{5}$ School of Medicine, Yasuj University \\ of Medical Sciences, Yasuj, Iran
}

\section{Video abstract}

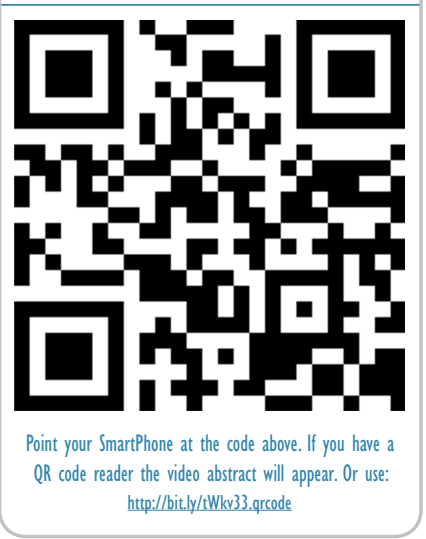

Correspondence: Hamid Reza Ghafarian Shirazi

Department of Social Sciences, Faculty of Medicine, Yasuj University of Medical Sciences, Yasuj, Iran

Tel +98 9173413596

Fax +98 74I 2230290

Email ghafarian_h@razi.tums.ac.ir
Background: Depression is a common psychiatric disorder worldwide, including in Iran, and is estimated to affect $10 \%-15 \%$ of the population. Antidepressant drugs can have multiple side effects, so a good choice of drug is important for successful treatment. This study compared the efficacy of nortriptyline with that of fluoxetine in the treatment of patients with major depressive disorder and assessed related factors, including age, gender, and level of education.

Methods: The study was a double-blind, randomized clinical trial with a six-month follow-up period. Participants were 120 patients aged 15-60 years with a diagnosis of major depressive disorder based on a psychiatry interview and the Beck depression rating scale, which were performed at the beginning, middle, and end of the study. The patients were treated with nortriptyline or fluoxetine. The paired $t$-test, independent $t$-test, and the $\mathrm{k}$ chi-square test were used to analyze the data.

Results: Twenty-three patients dropped out and 97 remained in the trial. Before intervention, the mean depression score was $32.85 \pm 6.23$ in the nortriptyline group and $33.12 \pm 6.50$ in the fluoxetine group. The results of the independent $t$-test showed a significant difference between depression score means before and after treatment in both groups. Changes at the end of the trial compared with baseline scores were $13.4 \pm 4.68$ and $16.96 \pm 4.96$ for nortriptyline and fluoxetine, respectively. Paired $t$-testing showed a significant difference in the mean depression score for both the nortriptyline and fluoxetine groups. Age, gender, and level of education had no significant effects on the outcome of treatment in the two groups.

Conclusion: The present study suggests that both nortriptyline and fluoxetine were effective in the treatment of depression, but that fluoxetine was more effective than nortriptyline after 3 and 6 months of treatment.

Keywords: major depressive disorder, nortriptyline, fluoxetine, treatment

\section{Introduction}

Depression is a common psychiatric disorder characterized by a number of signs and symptoms which may include depressed mood, anhedonia, insomnia, anorexia, difficulty in concentration, and suicidal thought. The lifetime prevalence of the condition in the general population is reported to be $10 \%-15 \%$, but in women has been reported to be up to $25 \% .^{1-3}$ Depression is much more common in women, occurring in a ratio of $2: 1$, and is the leading cause of disease-related disability in women. ${ }^{4,5}$ Mental health patterns in Iran are similar to those in other countries, but it seems that the prevalence of mental health disorders in Iran is lower than reported elsewhere. A review of the literature shows a prevalence rate for depression of $4.29 \%$ in Iran. ${ }^{6,7}$ 
Table I Baseline data for fluoxetine and nortriptyline groups

\begin{tabular}{lll}
\hline & $\begin{array}{l}\text { Nortriptyline } \\
\text { group }\end{array}$ & $\begin{array}{l}\text { Fluoxetine } \\
\text { group }\end{array}$ \\
\hline Female & 25 & 26 \\
Male & 24 & 22 \\
Age (mean \pm standard deviation) & $34.5 \pm 15.50$ & $35.1 \pm 14.80$ \\
Mean depression score before & $32.85 \pm 6.23$ & $33.12 \pm 6.50$ \\
intervention & & \\
\hline
\end{tabular}

Treatment of depression includes pharmacotherapy and psychotherapy. The common antidepressant drugs are tricyclic antidepressants, heterocyclic antidepressants, monoamine oxidase inhibitors, selective serotonin reuptake inhibitors (SSRIs), and sympathomimetics. ${ }^{8,9}$ The side effects of SSRI are reported to be nausea, headache, anger, weight loss, insomnia, yawning, diarrhea, weakness, fatigue, and dyspepsia. The side effects reported for tricyclic antidepressants include drowsiness, anticholinergic effects, weight gain, hypotension, tiredness, dullness, and tachycardia. Among the tricyclic antidepressants, nortriptyline is said to have the fewest complications. Fluoxetine was the first of the SSRIs to be introduced onto the US market and remains the most commonly used antidepressant agent in the US. ${ }^{10-13}$

There are some controversies about the effectiveness of nortriptyline and fluoxetine in the treatment of depression. While some studies have shown that nortriptyline is more effective than fluoxetine, ${ }^{13-16}$ others have shown fluoxetine to be more effective than nortriptyline. ${ }^{12,17,18}$ On the other hand, some studies have shown that there was no significant difference between the two drugs, ${ }^{19-21}$ although some researchers believe that there is a significant difference between the two drugs depending on age and gender. ${ }^{22}$ SSRIs are believed to be better tolerated and to have a better safety profile than the tricyclic antidepressants. ${ }^{20,23,24}$ The aim of this study was to compare the efficacy and patient satisfaction profile for nortriptyline with that of fluoxetine in the treatment of major depressive disorder and to determine the influence of related factors, including gender, age, and educational level, on outcome.

\section{Materials and methods}

This study was a randomized, double-blind, clinical trial with a 6-month follow-up period carried out in 120 patients referred to the Shahid Mofatteh Psychiatric Clinic, Yasuj, Iran, from 2007 to 2008 . The patients were selected by convenience sampling and randomized to one of two treatment groups. Twenty-three participants did not complete the study as a result of lack of cooperation, not taking the drugs regularly, and lack of punctuality. Inclusion criteria were being aged 15-60 years and a diagnosis of major depressive disorder on the basis of an interview and the Beck depression rating scale. Patients were excluded if they had received any antidepressant drug previously, had criteria for grief, adjustment disorder, major depressive disorder with psychotic features, had concomitant axis II or III disorder, a history of bipolar disorder, or schizophrenia. Women were excluded if they were pregnant or breast-feeding. Patients who did not respond to the drugs within 8 weeks were also excluded. This research was approved by the ethics committee and vice chancellor for research at Yasuj University of Medical Sciences. Patients were informed about the survey, and written consent was obtained from all participants or their legal guardians.

The study data were gathered from interviews with participants at the beginning of the study, and by clinical examination and using the Beck depression rating scale at the beginning, middle, and end of the study. The Beck depression inventory was used because it has been localized and validated for Iran. It also has appropriate reliability and validity. ${ }^{25,26}$ Both patients and the evaluating team were unaware of treatment allocation.

The patients received nortriptyline or fluoxetine treatment for 6 months. At the end of trial, 23 patients had withdrawn and 97 had remained. For the Beck depression

Table 2 Comparison of mean Beck depression scores according to age before and after 3 and 6 months of treatment with fluoxetine or nortriptyline

\begin{tabular}{|c|c|c|c|c|c|c|c|c|}
\hline \multirow[t]{2}{*}{ Age, years } & \multirow[t]{2}{*}{$\mathbf{n}$} & \multicolumn{3}{|c|}{ Nortriptyline } & \multirow[t]{2}{*}{$\mathbf{n}$} & \multicolumn{3}{|l|}{ Fluoxetine } \\
\hline & & Month 0 & Month 3 & Month 6 & & Month 0 & Month 3 & Month 6 \\
\hline$<20$ & 6 & $31.83 \pm 2.11$ & $24.12 \pm 3.67$ & $19.30 \pm 2.01$ & 5 & $32.60 \pm 2.8 \mid$ & $19.60 \pm 1.96$ & $15.40 \pm 2.05$ \\
\hline $20-30$ & 22 & $33.40 \pm 4.92$ & $23.18 \pm 4.10$ & $|9.72 \pm 4.3|$ & 25 & $33.32 \pm 4.21$ & $19.04 \pm 3.30$ & $16.20 \pm 4.11$ \\
\hline $30-40$ & 14 & $32.21 \pm 3.83$ & $23.22 \pm 3.78$ & $19.50 \pm 3.12$ & 12 & $33.08 \pm 3.90$ & $19.91 \pm 2.15$ & $16.30 \pm 3.27$ \\
\hline$>40$ & 7 & $32.31 \pm 2.95$ & $23.42 \pm 2.90$ & $19.85 \pm 1.78$ & 6 & $32.33 \pm 3.01$ & $19.10 \pm 1.98$ & $15.60 \pm 3.94$ \\
\hline All ages & 49 & $32.85 \pm 6.23$ & $23.65 \pm 4.48$ & $19.71 \pm 4.21$ & 48 & $33.12 \pm 6.50$ & $19.37 \pm 3.96$ & $16.16 \pm 4.02$ \\
\hline
\end{tabular}

Note: Analysis of variance $P>0.05$. 
Table 3 Comparison of mean Beck depression scores according to gender before and after 3 and 6 months of treatment with fluoxetine or nortriptyline

\begin{tabular}{|c|c|c|c|c|c|c|c|c|}
\hline \multirow[t]{2}{*}{ Gender } & \multirow[t]{2}{*}{$\mathbf{n}$} & \multicolumn{3}{|c|}{ Nortriptyline } & \multirow[t]{2}{*}{$\mathbf{n}$} & \multicolumn{3}{|l|}{ Fluoxetine } \\
\hline & & Month 0 & Month 3 & Month 6 & & Month 0 & Month 3 & Month 6 \\
\hline Female & 25 & $33.05 \pm 6.68$ & $24.43 \pm 5.21$ & $19.90 \pm 4.40$ & 26 & $32.70 \pm 6.93$ & $|8.93 \pm 4.1|$ & $16.34 \pm 5.0 \mid$ \\
\hline Male & 24 & $32.63 \pm 5.00$ & $23.30 \pm 4.17$ & $19.56 \pm 3.35$ & 22 & $33.40 \pm 5.81$ & $19.41 \pm 3.24$ & $15.90 \pm 3.49$ \\
\hline All level & 49 & $32.85 \pm 6.23$ & $23.65 \pm 4.48$ & $19.71 \pm 4.21$ & 48 & $33.12 \pm 6.5$ & $19.37 \pm 3.96$ & $16.16 \pm 4.02$ \\
\hline
\end{tabular}

inventory, a score $>10$ was considered to be depression, with $10-19$ scored as mild, $20-29$ as moderate, $30-39$ as partially severe, and $>40$ as severe depression..$^{27,28}$ All participants had a score $\geq 30$ (severe depression). Nortriptyline up to $150 \mathrm{mg} /$ day or fluoxetine up to $60 \mathrm{mg} /$ day was used for 6 months according to the severity of depression. Another self-developed questionnaire was used to record the age, gender, and educational level of the participants. Educational level was divided into four groups, ie, illiterate, primary school, high school, and university graduate. For illiterate cases, the questions were read out verbally and a complete verbal explanation was given.

A questionnaire was developed to measure the patient's satisfaction with their trial medication and any side effects. It consisted of 11 items measured on a three-point Likert scale $(1=$ unsatisfied, $2=$ fairly satisfied, $3=$ satisfied $)$. The reliability of the instruments was measured using Cronbach's alpha. The reliability index was good at 8.41. Drug side effects were also recorded.

\section{Statistical analysis}

The paired $t$-test was used to compare mean Beck test scores for each group before and after treatment. The independent $t$-test was used to compare the means of the two groups at baseline, and at 3-month and 6-month follow-up. Paired $t$-tests were used to compare mean depression scores at the beginning of treatment with those at the 3-month and 6-month follow-up. The total score for satisfaction in terms of side effects and treatment outcome was estimated, and using cutoff points of 40 and 60 was converted into qualitative scores of satisfied, partially satisfied, and unsatisfied. Fisher's Exact test was then used to calculate the total satisfaction scores for the two treatment groups. The results are presented as the mean \pm standard deviation, and the significance level was set at $P<0.05$.

\section{Results}

There were approximately equal numbers of men and women in both treatment groups, and the mean age was 35 years (Table 1). Tables 2-4 show that there was no significant difference between the two groups with regard to basic demographic data including age, gender, and educational level. The results also indicate that there was no significant difference between the two groups for mean Beck depression test scores before intervention. However, there was a significant difference for these scores between the groups after 3 and 6 months of treatment (Table 5). Both drugs were effective in major depression at 3 and 6 months of follow-up, but fluoxetine was more effective than nortriptyline (Figure 1). The results also indicate that there was a significant difference between the groups for mean Beck depression score before and after 3 and 6 months of treatment $(P<0.05$, Table 5$)$. The descriptive statistics shown in Table 5 indicate that the changes in mean Beck depression score at the end of the study compared with baseline was $16.96 \pm 4.96$ and $13.14 \pm 4.68$ for fluoxetine and nortriptyline, respectively.

Both drugs had side effects, including headache, drowsiness, constipation, anorexia, nausea, and vomiting. Fluoxetine was significantly correlated with nausea while nortriptyline was not. Nortriptyline was significantly correlated with headache, dizziness, drowsiness, weakness, aggression, and constipation (Table 6). Total satisfaction

Table 4 Comparison of mean Beck depression scores based on educational level before and after 3 and 6 months of treatment with fluoxetine or nortriptyline

\begin{tabular}{|c|c|c|c|c|c|c|c|c|}
\hline \multirow[t]{2}{*}{ Educational level } & \multirow[t]{2}{*}{$\mathbf{n}$} & \multicolumn{3}{|c|}{ Nortriptyline } & \multirow[t]{2}{*}{$\mathbf{n}$} & \multicolumn{3}{|l|}{ Fluoxetine } \\
\hline & & Month 0 & Month 3 & Month 6 & & Month 0 & Month 3 & Month 6 \\
\hline Not educated & 21 & $33.10 \pm 6.99$ & $24.10 \pm 4.21$ & $19.90 \pm 4.40$ & 20 & $32.65 \pm 2.93$ & $19.03 \pm 3.11$ & $16.24 \pm 4.01$ \\
\hline Low educated & 16 & $32.80 \pm 5.00$ & $23.50 \pm 4.67$ & $19.06 \pm 4.35$ & 17 & $33.40 \pm 2.91$ & $19.91 \pm 4.34$ & $15.90 \pm 4.29$ \\
\hline High educated & 12 & $32.33 \pm 5.76$ & $23.31 \pm 4.24$ & $19.52 \pm 3.97$ & 11 & $32.90 \pm 2.45$ & $19.80 \pm 3.99$ & $16.02 \pm 3.98$ \\
\hline All levels & 49 & $32.85 \pm 6.23$ & $23.65 \pm 4.48$ & $\mid 9.71 \pm 4.21$ & 48 & $33.12 \pm 6.50$ & $19.37 \pm 3.96$ & $16.16 \pm 4.02$ \\
\hline
\end{tabular}


Table 5 Mean Beck scores for depressed patients referring to Yasuj Psychiatric Clinic, Iran, by time and kind of treatment

\begin{tabular}{lllll}
\hline & Month 0 & Month 3 & Month 6 & Total decrease after 6 months \\
\hline Nortriptyline & $32.85 \pm 6.23^{* *}$ & $23.65 \pm 4.48$ & $19.71 \pm 4.21$ & $13.14 \pm 4.68$ \\
Fluoxetine & $33.12 \pm 6.50$ & $19.37 \pm 3.96$ & $16.16 \pm 4.02$ & $16.96 \pm 4.96$ \\
Significance (t-test) & $P>0.05$ & $P<0.05$ & $P<0.05$ & - \\
\hline
\end{tabular}

Note: **Mean \pm standard deviation.

with the drugs was estimated by patient perception of side effects, and the outcomes were compared between the two groups. The results indicated the patients were more satisfied with fluoxetine than with nortriptyline (Table 7).

\section{Discussion}

Depression is a common psychiatric disorder which may cause depressed mood, anhedonia, insomnia, anorexia, difficulty in concentration, and suicidal thought. It can be treated by both psychotherapy and pharmacotherapy. Tricyclic antidepressants and SSRIs are drugs commonly used in the treatment of depression. This study compared the efficacy of nortriptyline (a tricyclic antidepressant) and fluoxetine (an SSRI) in the treatment of patients with major depressive disorder. Its findings suggest that both nortriptyline and fluoxetine were effective, which is in agreement with other studies. However, fluoxetine was more effective than nortriptyline in the treatment of major depressive disorder, and age, gender, and educational level of the patients did not have a significant impact on the treatment.

Our results are different from those of previous studies reported by Fabre et al, Roose et al, Akhondzadeh et al, and Robinson et al. ${ }^{13-16}$ These reported that nortriptyline was more effective than fluoxetine. Roose et al also reported that nortriptyline was more effective than fluoxetine in depression with melancholic features. Our results are also different in this respect from the studies reported by Anderson et al, Finkel et al, and Song et al, ${ }^{19-21}$ Further, unlike Joyce et al, who reported that older male melancholic patients had a

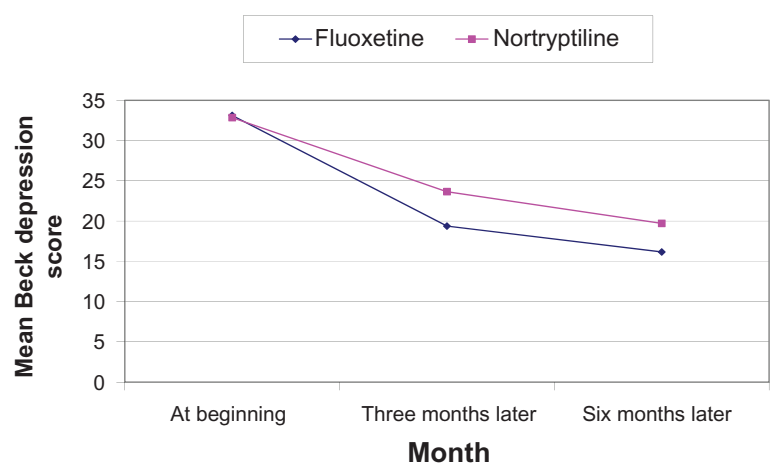

Figure I Comparison of mean Beck depression scores for patients referred to Yasuj Psychiatry Clinic according to treatment allocation. markedly superior response to nortriptyline compared with fluoxetine, and that young female melancholic patients had a markedly superior response to fluoxetine, ${ }^{22}$ the results of our study showed that fluoxetine is more effective than nortriptyline but with no effect of age and gender.

However, the results of our study are similar to those of Khade et al, Attari et al, Bhurghri et al, and Anderson et al. ${ }^{12,17-19}$ In our study, fluoxetine was compared with nortriptyline, but in the study by Khade et al nortriptyline was compared with fluvoxamine (an SSRI), and fluvoxamine was reported to be better than nortriptyline. ${ }^{12}$

In terms of toxicity, it could be argued that both drugs had some side effects. In our study fluoxetine was associated with nausea, similar to other studies. ${ }^{10-13,23,24}$ Meanwhile, Khade et al and Otsubo et al reported that fluvoxamine was associated with nausea and Uher et al reported that escitalopram was associated with insomnia, diarrhea, and yawning. 10,12,24 In our study, fluoxetine was significantly associated with nausea, whereas Bhurghri et al reported that nortriptyline was significantly associated with nausea and headache. ${ }^{18}$ Our results indicate that nortriptyline was not significantly associated with dry mouth, but other studies have found this relationship. In our study, nortriptyline was significantly associated with headache, dizziness, constipation, drowsiness, weakness, and aggression, which seems to be in line with other studies. ${ }^{10-13,23,24}$ Khade et al reported that drowsiness, tiredness, and dullness were related to this drug, and Uher et al further reported that dry mouth, constipation, and weight gain were associated with nortriptyline. ${ }^{10,12}$

Table 6 Mean percent frequency of treatment-emergent adverse events

\begin{tabular}{llll}
\hline & & & Significance $\left(\chi^{2}\right.$ test $)$ \\
\hline Headache & $24(48.9)$ & $17(35.4)$ & 0.026 \\
Dizziness & $18(36.7)$ & $8(16.3)$ & 0.018 \\
Constipation & $13(26.5)$ & $2(4.2)$ & 0.016 \\
Drowsiness & $15(30.6)$ & $4(8.3)$ & 0.005 \\
Weakness & $25(51.0)$ & $11(22.9)$ & 0.01 \\
Dry mouth & $1(2.1)$ & $3(6.3)$ & 0.17 \\
Aggression & $25(51.0)$ & $4(8.3)$ & 0.001 \\
Hypersomnia & $14(28.6)$ & $12(25.0)$ & 0.39 \\
Nausea, vomiting & $0(0)$ & $17(35.4)$ & 0.045 \\
Anorexia & $16(33.3)$ & $17(35.4)$ & 0.45 \\
\hline
\end{tabular}

Note: All numbers are written as frequency (\%). 
Table 7 Satisfaction profile for nortriptyline and fluoxetine in depressed patients referred to Yasuj Psychiatry Clinic, Iran

\begin{tabular}{lllll}
\hline Satisfaction & Dissatisfied & $\begin{array}{l}\text { Partially } \\
\text { satisfied }\end{array}$ & Satisfied & Total \\
\hline Drug & & & & \\
Nortriptyline & $9(18.4)$ & $33(67.3)$ & $7(14.3)$ & $49(100)$ \\
Fluoxetine & $5(10.4)$ & $22(45.8)$ & $21(43.75)$ & $48(100)$ \\
\hline
\end{tabular}

Notes: $\chi^{2}=15.2 ; \mathrm{DF}=3 ; P<0.012$; all numbers are written as frequency (\%).

Based on the results of our study, which are consistent with those of Finkel et al, Kasper et al, and Otsubo et al, ${ }^{20,23,24}$ it could be argued that the patient satisfaction and tolerability profiles of fluoxetine are better than those of nortriptyline (Table 7). Finally, we can conclude that fluoxetine and nortriptyline are effective in major depressive disorder, but that fluoxetine was more effective than nortriptyline, and age, gender, and educational level did not contribute to the efficacy profiles of these drugs.

\section{Acknowledgments}

The authors thank all the patients who participated in this study along with their families. They are also grateful to staff of the Research Center of Social Factors Affecting Health, Yasuj University of Medical Sciences, for their support, and our colleagues in Rajaee Hospital, Shahid Mofatteh Psychiatric Clinic, and the vice chancellor for research, Yasuj University of Medical Sciences for assistance with this study.

\section{Disclosure}

The authors report no conflicts of interest in this work.

\section{References}

1. Kessler RC, Walters EE. Epidemiology of DSMIII-R major depression and minor depression among adolescents and young adults in the National Comorbidity Survey. Depress Anxiety. 1998;7:3-14.

2. Hirschfield R. Major depression, dysthymia and depressive personality disorder. Br J Psychiatry Suppl. 1994;26:23-30.

3. Kaelber CT, Moul DE, Farmer ME, et al. Epidemiology of depression. In: Beckham EE, Leber WR, editors. Handbook of Depression. 2nd ed. New York, NY: Guilford Press; 2009.

4. Kessler RC. Epidemiology of women and depression. $J$ Affect Disord. $2003 ; 74: 5-13$

5. Weissman MM, Bland R, Joyce PR, et al. Sex difference in rates of depression: cross-national perspective. J Affect Disord. 1993;29: 77-84.

6. Mohammadi MR, Davidian H, Noorbala AA, et al. An epidemiological survey of psychiatric disorders in Iran. Clin Pract Epidemiol Ment Health. 2005;1:16.

7. Noorbala AA, Bagheri Yazdi SA, Yasamy MT, Mohammad K. Mental health survey of the adult population in Iran. Br J Psychiatry. 2004; 184:70-73.

8. Gelder M, Mayou R, Geddes J. Concise Oxford Textbook of Psychiatry. 2nd ed. New York, NY: Oxford University Press; 1999.
9. Sadock SJ, Kaplan HI, editors. Mood disorders: clinical features. In: Kaplan and Sadock's Synopsis of Psychiatry. 9th ed. Philadelphia, PA: Lippincott Williams and Wilkins; 2003.

10. Uher R, Farmer A, Henigsberg N, et al. Adverse reactions to antidepressants. Br J Psychiatry. 2010;192:202-207.

11. Daly EJ, Trivedi MH, Fava M, et al. The relationship between adverse event during selective serotonin reuptake inhibitor treatment for major depressive disorder and non remission in the suicide assessment methodology study. J Clin Psychopharmacol. 2011;31: 31-38.

12. Khade A, Basir M, Kale AS, Turankar A. Study of the effect of nortriptyline and fluvoxamine on psychomotor functions in healthy volunteers. Indian J Psychol Med. 2010;32:104-107.

13. Fabre LF, Scharf MB, Itil TM. Comparative efficacy and safety of nortriptyline and fluoxetine in the treatment of major depression: a clinical study. J Clin Psychiatry. 1991;52 Suppl:62-67.

14. Roose SP, Glassman AH, Attia E, et al. Comparative efficacy of selective Serotonin reuptake inhibitors and Tricyclic in the treatment of melancholia. Am J Psychiatry. 1994;151:1735-1739.

15. Akhondzadeh S, Faraji H, Sadeghi M, Afkham K, Fakhrzadeh H, Kamalipour A. Double-blind comparison of fluoxetine and nortriptyline in the treatment of moderate to severe major depression. J Clin Pharm Ther. 2003;28:379-384.

16. Robinson RG, Schultz SK, Castillo C, et al. Nortriptyline versus fluoxetine in the treatment of depression and in short-term recovery after stroke: a placebo-controlled, double-blind study. Am J Psychiatry. 2000;157:351-359.

17. Attari A, Moghadam Y, Hassanzadeh MS, et al. Comparison of efficacy with nortriptyline and fluoxetine in treatment of major depression in children and adolescents: a double blind study. J Res Med Sci. 2006;11:24-30.

18. Bhurghri GR, Korejo HB, Qureshi MA. Role of fluoxetine and nortriptyline in major depressive disorders. Rawal Medical Journal. 2011;36:38-40.

19. Anderson IM, Tomenson BM. The efficacy of selective serotonin reuptake inhibitors in depression: a meta analysis of studies against tricyclic antidepressants. J Psychopharmacol. 1994;8:238-249.

20. Finkel SI. Efficacy and tolerability of antidepressant therapy in the old-old. J Clin Psychiatry. 1996;57 Suppl:23-28.

21. Song F, Freemantle N, Sheldon TA, et al. Selective reuptake inhibitors: meta analysis of efficacy and acceptability. Br Med J. 1993; 306:683-687.

22. Joyce PR, Mulder RT, Luty SE, McKenzie JM, Rae AM. A differential response to nortriptyline and fluoxetine in melancholic depression: the importance of age and gender. Acta Psychiatr Scand. 2003;108:20-23.

23. Kasper S, Hoflich G, Scholl HP, et al. Safety and antidepressant efficacy of selective serotonin re-uptake inhibitors. Hum Psychopharmacol. 1994;9:1-12.

24. Otsubo T, Akimoto Y, Yamada H, et al. A comparative study of the efficacy and safety profile between fluvoxamine and nortriptyline in Japanese patients with major depression. Pharmacopsychiatry. 2005;38:30-35.

25. Ghassemzadeh H, Mojtabai R, Karamghadiri N, Ebrahimkhani N. Psychometric properties of a Persian-language version of the Beck depression inventory - second edition: BDI-II-PERSIAN. Depress Anxiety. 2005;21:185-192.

26. Dadsetan B, Mansori A. Validity and reliability of Beck depression test in social survey. 1987;2:12-23. In Farsi.

27. Beck AT, Steer RA, Garbin MG. Psychometric properties of the Beck depression inventory. Clin Psychol Rev. 1988;77:100.

28. Dobson KS, Mohammad Khani P. Psychometric characteristics of the Beck Depression Inventory. Journal of Rehabilitation. 2007;29:82. Farsi. 


\section{Publish your work in this journal}

Clinical Pharmacology: Advances and Applications is an international, peer-reviewed, open access journal publishing original research, reports,

reviews and commentaries on all areas of drug experience in humans.

The manuscript management system is completely online and includes

a very quick and fair peer-review system, which is all easy to use. from published authors.

Submit your manuscript here: http://www.dovepress.com/clinical-pharmacology-advances-and-applications-journal 